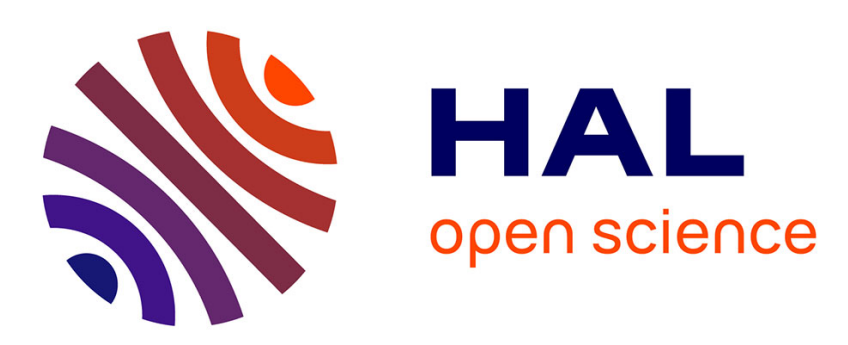

\title{
Call rate, fundamental frequency, and syntax determine male-call attractiveness in blue petrels Halobaena caerulea
}

Charlène Gémard, Thierry Aubin, Eliette Reboud, Francesco Bonadonna

\section{To cite this version:}

Charlène Gémard, Thierry Aubin, Eliette Reboud, Francesco Bonadonna. Call rate, fundamental frequency, and syntax determine male-call attractiveness in blue petrels Halobaena caerulea. Behavioral Ecology and Sociobiology, 2021, 75 (3), 10.1007/s00265-021-02989-3 . hal-03146426

\author{
HAL Id: hal-03146426 \\ https://hal.science/hal-03146426
}

Submitted on 31 Aug 2021

HAL is a multi-disciplinary open access archive for the deposit and dissemination of scientific research documents, whether they are published or not. The documents may come from teaching and research institutions in France or abroad, or from public or private research centers.
L'archive ouverte pluridisciplinaire HAL, est destinée au dépôt et à la diffusion de documents scientifiques de niveau recherche, publiés ou non, émanant des établissements d'enseignement et de recherche français ou étrangers, des laboratoires publics ou privés. 
1 Call rate, fundamental frequency and syntax determine

2 male-call attractiveness in blue petrels Halobaena caerulea

3 Charlène Gémard ${ }^{1,2^{*}}$, Thierry Aubin $^{2}$, Eliette L. Reboud ${ }^{1}$, Francesco Bonadonna ${ }^{1}$

$4 \quad{ }^{1}$ CEFE, Univ Montpellier, CNRS, Univ Paul Valéry Montpellier 3, EPHE, IRD, Montpellier, France

$5 \quad 2$ Equipe Communications Acoustiques, UMR 9197, Neuro-PSI-CNRS, Université Paris-Sud, Bat.446, 91405

6 Orsay, France.

7 *Corresponding author: C. Gémard (charlene.gemard@ @efe.cnrs.fr) (https://orcid.org/0000-0002-8019-5842)

8 


\section{Abstract}

In blue petrels (Halobaena caerulea), females are supposed to be particularly choosy and mate choice can take a couple of years. In these lifelong monogamous seabirds, choosing a good mate is crucial and has a strong influence on their fitness. Due to their nocturnal habits, the absence of sexual dimorphism and the physical barrier between males calling from their burrow and females flying above the colony, vocal signals seem to be one of the main channels for males to communicate with potential mates. In a previous study, we investigated whether acoustic parameters of male calls carry information about morphological characteristics that might be indicators of males' qualities. Here, we experimentally test whether these acoustic parameters linked to male characteristics are actually attractive to females. To do so, we played-back modified calls of males to females in a colony of blue petrels of the Kerguelen archipelago. We found that flying females were more attracted by high-pitched calls, and by calls broadcasted at a high call rate. Previous studies showed a relationship between pitch and bill depth and length. In filter-feeding birds, such as blue petrels, bill morphology influences feeding efficiency. A high call rate is an indicator of sexual motivation and makes the caller easier to locate by potential mates and predators in the hubbub of the colony. We thus hypothesized that producing frequent high-pitched calls may be the result of a trade-off between predation avoidance and conspicuous sexual signalling.

\section{Significance statement}

Mate selection process is largely unknown in burrowing petrels due to their cryptic life at the colony. Here, we examined the implication of vocal signals in mate choice in the blue petrel Halobaena caerulea. We used an experimental setting based on a two-choice test to show that male calls are sexual signals attracting females. As expected, broadcasting male calls attracted females. Despite the apparent stereotypy of male calls, their acoustic parameters transmit pieces of information that may influence females' preference. We found that females are more attracted by high call rate and high-pitched calls. This is the first evidence of the implication and influence of vocal signals in mate choice in burrowing petrels.

Keywords Vocal communication, sexual signal, attractiveness, mate choice, seabird, blue petrel 


\section{Compliance with ethical standards}

\section{Funding}

The study was financially supported by the French polar institute Paul Emile Victor (IPEV) This work was carried out under the IPEV research program no. 354 ETHOTAAF.

\section{Conflicts}

The authors declare that they have no conflict of interests.

\section{Ethics approval}

All experiments were approved by the French Ethical Committee (APAFIS\#9496-201707131540776) after favourable recommendation of Comité d'Ethique pour L'Expérimentation Animale LanguedocRoussillon (CEEA-LR), C2EA n³6, and by the Ethical Committee of Reserve Naturelle des Terres Australes et Antarctiques Françaises (TAAF). Experiments were made in full conformity with guidelines established by both IPEV and CNRS for the Ethical Treatment of Animals. All experiments comply with the current laws of the country where they were performed.

\section{Consent to participate}

This article does not contain any studies involving human participants performed by any of the authors.

\section{Consent for publication}

All authors have approved the submitted version; and have agreed both to be personally accountable for the author's own contributions and to ensure that questions related to the accuracy or integrity of any part of the work, even ones in which the author was not personally involved, are appropriately investigated, resolved, and the resolution documented in the literature.

\section{Availability of data and material}

The dataset generated and analysed during the current study is available in supplementary material.

\section{Code availability}

Not applicable

\section{Authors' contributions}


61 All authors made substantial contributions to conception of experiment, analysis and interpretation of 62 data, and critical review of the manuscript. Charlène Gémard, Francesco Bonadonna and Thierry Aubin 63 contributed to the study conception and design. Charlène Gémard and Francesco Bonadonna performed material preparation and data collection. Charlène Gémard and Eliette L. Reboud analysed the data. The first draft of the manuscript was written by Charlène Gémard and all authors commented on previous versions of the manuscript. All authors read and approved the final manuscript.Acknowledgments

67 We are very grateful to the French polar institute Paul Emile Victor (IPEV) which financially and logistically supported our work. We thank Jessica Graham who improved the English of this manuscript, and Guilhem Battistella and Jean-Yves Barnagaud for their precious help on the field. 


\section{Introduction}

In animal species, mating is not random and the probability of mating with a given individual of the opposite sex increases with some behaviour patterns (Halliday 1983). According to theoretical and empirical studies, in many species, both males and females should profit from being choosy when selecting their mating partner (Courtiol et al. 2016). To do so, they rely on attractive signals that inform them about the signaller's qualities (Smith 1991). Although sexual signals are often multimodal, the implication of vocal signals in mate choice have been well documented in many taxa. Male vocalizations attract potential mates in insects (Walker 1957), fish (Amorim et al. 2006), frogs (Ryan 1980), bats (Knornschild et al. 2017), songbirds (Mountjoy \& Lemon 1991), and non-songbirds (Gibson 1989; Martín-Vivaldi et al. 1999).

To highlight the influence of vocal signals in mate choice, two criteria have to be respected: (i) males/females must show a preference for certain acoustic parameters of calls/songs when these are presented in the absence of the caller/singer, and (ii) the same acoustic parameters correlate with the caller/singer's mating success in natural conditions (Searcy \& Andersson 1986). Well-known examples of attractive acoustic parameters in birds and mammals are a low fundamental frequency (F0 or pitch), a high vocalizing rate, long vocalizations, and vocalizations consisting in many elements (for a review: Nowicki \& Searcy 2004). These parameters reflect some overall qualities, such as morphological characteristics (e.g. body size: Ballentine et al. 2004; Ballentine 2009; Byers et al. 2016; Favaro et al. 2017; Kriesell et al. 2018; bill morphology: Christensen et al. 2006), endurance, and fighting abilities (McComb 1991). These parameters are also related to breeding success in natural conditions (Chastel et al. 1995; Salton et al. 2015).

Most of our knowledge on vocal signal implication in mate choice focuses on songbirds. Comparatively, non-songbirds, such as seabirds, have been poorly documented, although mate choice is crucial in these species due to their particular breeding ecology (for a review see Bried \& Jouventin 2002). Seabirds have distinct feeding and nesting areas: they feed at sea, while they breed on land. This implies obligatory bi-parental care and cooperation between mates during the whole breeding cycle. Burrowing petrels (Procellariforms) are colonial seabirds breeding in self-dug burrows on coastal grass 
slops (Warham 1990), to which they show a high fidelity year after year (Bried \& Jouventin 2002). They form lifelong monogamous pairs, and divorces and extra-pair copulations are rare (Jouventin \& Mougin 1981; Warham 1990, 1996; Quillfeldt et al. 2012). Pairs lay a single egg per year with no possibility of replacement clutch in case of failure and partners alternate several-day fasting periods in the burrow and feeding trips at sea to restore energy (Warham 1990). Parental investment is thus high and parental care is based on parents' cooperation and synchrony. In addition, with respect to species that can change partner at each breeding, correcting possibly wrong choices, these petrels are lifelong faithful to the mate. Consequently, choosing the wrong partner will affect the lifelong fitness more drastically than in other species.

Bachelor petrel males actively call at night from their burrow while females fly calling over the colony. This behaviour may be considered intriguing as calling in the colony exposes petrels to predators, especially the brown skua (Stercorarius antarcticus) which uses the sexual calls of petrels to locate and catch them (Mougeot \& Bretagnolle 2000b). Blue petrels, Halobaena caerulea, and prions Pachyptila sp are among their preys. Therefore, considering the high predation cost associated with their production, vocal signals should play a major role in mate choice. After hearing a male call, females can land close to the sound source, then enter the caller's burrow where they may start to perform extensive duets (Storey 1984). It suggests that vocal signals are essential in mate choice, although it has not been experimentally tested. Additional signals may be involved, such as olfactory signals to gather genetic information (e.g. MHC) from the potential mate (Leclaire et al. 2017). After pairing mates are silent and would rather use olfactory signals to find their burrow when returning to the colony at night (Bonadonna \& Nevitt 2004; Bonadonna \& Sanz-Aguilar 2012; Leclaire et al. 2017). Females visit several males for a couple of years before pairing (Bretagnolle 1996), suggesting that the mate choice by females is active, and that male calls attract and/or stimulate potential mates (Bretagnolle 1990; Warham 1990).

It has been shown recently that male calls carry information about the caller's morphological characteristics, such as wing morphology, body size and bill shape (e.g. blue petrels: Gémard et al. 2019; Genevois \& Bretagnolle 1994; Antarctic prions Pachyptila desolata: Gémard et al. 2019). Big males with a long, thin bill produce high-pitched calls consisting of many syllables. Males with long and thin wings produce fast calls (high syllable rate). These morphological characteristics are linked to male 
overall qualities and reproductive success: for instance, bill morphology is related to filter-feeding efficiency (Klages \& Cooper 1992), wing morphology to foraging behaviour (Weimerskirch et al. 1995) and body condition to reproductive success (Chastel et al. 1995).

Females landing on the ground after hearing a male call is seemingly the first step of the mate choice process in burrowing petrels described in literature (Bretagnolle 1996; Brooke 2004; Warham 1990; Warham 1996). Despite the seeming implication of vocal signals in mate choice, vocal communication in burrowing petrels has been poorly studied so far, likely due to constraints associated with fieldwork in remote locations and their particular breeding ecology (nocturnal and burrowing habits). Although the suggestion that acoustic parameters of male calls reflect qualities and mating success, the hypothesis that females actually show a preference for these parameters has never been tested and thus we do not know if calls are signals in mate choice. Here, we proposed to test this hypothesis by assessing whether females are actually attracted by male calls, and more precisely by certain acoustic parameters of these calls.

We experimentally tested by playback experiments with modified calls: (i) the role of male calls in mate attraction, and (ii) the role of certain acoustic parameters of male calls in mate choice. Among burrowing petrels, the blue petrel is a good candidate to assess this question because it is highly vocal and suffers from a high predation pressure (more than $70 \%$ of the brown skua diet: Montcorps et al. 1998). Based on our previous study on the informative content of blue petrels' calls (Gémard et al. 2019), we hypothesized that females should be attracted by males producing long calls with many syllables and a high syllable rate. According to the handicap theory (Zahavi 1975; Zahavi 1977), females may also be attracted by males that take large risks of predation, for instance by calling at a high call rate and/or producing long calls as shown in other species (Johnstone 1995; Zuk \& Kolluru 1998).

\section{Material and methods}

\section{Study area}

We conducted the fieldwork on a small island of the Kerguelen Archipelago (Ile Verte: $\left.49^{\circ} 510^{\prime} \mathrm{S}, 70^{\circ} 050^{\prime} \mathrm{E}\right)$, southern Indian Ocean. In blue petrels $H$. caerulea, bachelor males and females are vocally active and actively prospecting for a mate in the colony, at night, throughout the breeding 
season (Warham 1996), although the daily activity in the colony is dependant of the moon phase and clouds cover (Mougeot \& Bretagnolle 2000a). We thus conducted the fieldwork during the birds' incubation period, from November $27^{\text {th }}$ to December $27^{\text {th }} 2018$.

\section{Studied species}

In blue petrels, callers are mainly bachelor males and females, although breeders call when they are vocally challenged by a conspecific, likely to defend their burrow (Warham 1996). Their calls consist of a repetition of distinct phrases, themselves composed of indivisible elements called syllables (Bretagnolle 1996; Catchpole \& Slater 2008). There are four types of syllable (mentioned as A, B, C, $\mathrm{D}$, in their order of appearance), distinguishable by the shape of their frequency modulations. Syllable $\mathrm{C}$ is repeated between two and twelve times depending on the individuals (Fig. 1).

\section{Playback procedure}

We tested the attractiveness of five acoustic parameters related to morphological characteristics in blue petrels: call rate, call duration, energy spectrum, number of syllables per phrase, and syllable rate (Gémard et al. 2019). To do so, we used a two-choice playback experiment consisting in broadcasting two versions (high or low) of a representative call of males, from inside two artificial burrows at the same time. The two representative calls were calls for which syntax, temporal parameters and frequencies are close to the mean values of the population, based on measurements of 38 acoustic parameters presented (Appendix 1). Playbacks were emitted using a Sony NWE393B connected to a JBL Flip 4 speaker (frequency response: $60 \mathrm{~Hz}-12000 \mathrm{~Hz} \pm 5 \mathrm{~dB}$ ). The volume occupied by the speaker is close to the volume occupied by a blue petrel (about $0.7 \mathrm{~L}$ ). Playbacks were broadcast during the most intense vocal activity (10:00 pm to 3:00 am, unpublished data) at a natural amplitude (mean \pm SD: 66 \pm $9 \mathrm{~dB}$, measured at the entrance of burrows with decibel-meter on 115 spontaneous calls from 24 bachelor males in the studied population) and a natural call rate (a call every $40 \mathrm{~s}$, unpublished data from 21 bachelor males in the studied population), except when we specifically tested the call rate attractiveness.

Signals to broadcast were synthetized using the signal processing software Avisoft-SASLab Pro v 5.2.11 (Specht 2017). To obtain dyads of experimental signals, a single call (or exemplar) was recorded from two male individuals (hereafter call1 and call2). Call1 and call2 were chosen, among calls recorded 
in 2017, to have the mean parameters observed in the studied population (i.e. a call for which length, number and structure of syllables are close to the mean values of the population). To create dyads, we modified each of the two calls by decreasing and increasing a selected acoustic parameter, letting the other parameters unchanged. This gave us dyads of stimuli for each parameter: a low-parameter-call and a high-parameter-call (Table 1). To avoid extreme values and bias related to supra stimulus, we increased/decreased the selected acoustic parameter in the natural range previously observed in the studied colony (Appendix 1). Considering five acoustic parameters, we obtained five dyads for call1 and five dyads for call2.

We repetitively broadcast the experimental signals from inside an unoccupied artificial-burrow chamber of the same size (volume about $4.8 \mathrm{~L}$ ) to limit biases of sound propagation caused by volume differences. Artificial burrows were installed during the previous breeding season in the colony (2017). They consisted in a chamber made of a clay pot diameter $30 \mathrm{~cm}$ upside down, a 66-centimetre tunnel made of two end-to-end half fired-clay wine rack, and a 30-centimetre PVC pipe diameter $125 \mathrm{~mm}$ above the chamber to easily reach the birds and/or the egg. They were buried at a depth of $40 \mathrm{~cm}$ and covered by the existing vegetation. A wooden board and a stone recovered the hole above the chamber, as the other monitored burrows of the colony (see Appendix 2 for pictures). During the 2018 breeding season, $75 \%$ of artificial burrows installed in 2017 were occupied by breeding petrels.

To control the nest effect, we used two randomly selected burrow twosome successively: twosome "A" (made of burrows Aa and $\mathrm{Ab}$ ), then burrow twosome "B" (made of burrows Ba and $\mathrm{Bb}$ ). The two burrows of a twosome were at least five meters apart and had different orientation to avoid the influence of sound propagation from a burrow to the other burrow. Each dyad of call1 was tested twice the burrow twosome A: one night the low-parameter-call was in burrow Aa and the high-parameter-call in the burrow $\mathrm{Ab}$, the next night the reverse situation with the same dyad. Each dyad of call2 was then tested twice the burrow twosome B following the same scheme described above.

We equipped each burrow with two infrared phototraps (Bushnell Nature View Essential HD Camera) to record female behaviours at proximity of the tested burrows (Fig. 2, Appendix 3). We placed phototraps $50 \mathrm{~cm}$ above the ground on wooden sticks at equidistance of the burrow entrance. We oriented phototraps toward the burrow entrance. We used phototraps in video mode with both automatic 
detection (i.e. one-minute record after movement detection) and "Field Scan" option (i.e. automatic oneminute record every five minutes).

Videos were analysed by a blind-to-the-experiment student with VLC media player 2.1.5 Rincewind. In several burrowing-petrel species, bachelor females use a two-step approach: first flying and landing close to the sound source, then listening to calls until they reach the source by walking (Storey 1984). Here, for each night and each burrow, we counted the number of females flying close to the burrow and the number of females on the ground. We calculated the total time each female spent on the ground. To limit the risk of considering breeders shifting and transient individuals, we only considered individuals flying at a maximum distance of five meters from the burrow entrance, and individuals showing exploration behaviours on the ground, e.g. calling, walking, moving head in the direction of the burrow (Appendix 4).

\section{Data analyses}

All analyses results were implemented under the R software environment version 3.4.4 (R Core Team 2018). Raw data are available in Appendices 5 and 6.

We used three distinct models to compare the attractiveness of the increased parameter and the decreased for each five acoustic parameters: one for the number of females flying close to the burrow, one for the number of females on the ground close to the burrow, and one for the time females spent on the ground. To model the number of females flying as a function of the covariates, a Negative Binomial General Linear Model (NB GLM) with a with a log link function was used. NB GLM is appropriate for count and over-dispersed data. To model the number of females on the ground as a function of the covariates, a Poisson GLM with a log link function was used. Poisson distribution is typically used for count data. To model the time females spent on the ground as a function of the covariates, a Linear Model from the lme4 R package (Bates et al. 2015) was used. The "total time" variable was previously log-transformed to normalize its distribution. The three models included the following categorical variables as fixed effects: burrow twosome (A or B), and the interaction between acoustic parameter and condition (low or high). Model assumptions were verified by plotting residuals versus fitted values (Appendices 7, 8, and 9). For each of the three selected models, we created a contrast matrix based on 

the attractiveness of parameters between each other.

\section{Results}

\section{Number of Females Flying}

Model assumptions were verified (dispersion parameter $=1.02$ : residuals in Appendix 7). Results showed significant differences between the maximum and the minimum in two acoustic parameters (Table 2). More specifically, a high call rate attracted more flying females than a low call rate (estimate $(\mathrm{SE})=2.12(0.90), z=2.35, p<0.05$ : Table 2$)$. High-pitched calls attracted more flying females than low-pitched calls (estimate $(\mathrm{SE})=1.94(0.89), z=2.18, p<0.05$ : Table 2). Based on the model parameters, calls with phrases made of few syllables might also be more attractive than calls with phrases of many syllables, although the relationship is not significant (estimate (SE) $=-1.94(1.03), z=$ $-1.88, p=0.06$ : Table 2, Fig. 3). Burrow twosome A was significantly more attractive than burrow twosome B (estimate $\left.(\mathrm{SE})=-2.06(0.42), z=-4.9, p<10^{-6}\right)$.

Number of Females on the Ground

Model assumptions were verified (dispersion parameter $=4.12$ : residuals in Appendix 8). Results show that a high call rate significantly attracted more females on the ground than a low call rate (estimate $(\mathrm{SE})=1.22(0.51), z=2.41, p<0.05$ : Table 3, Fig. 4). Burrow twosome A was significantly more attractive than burrow twosome B (estimate $(\mathrm{SE})=-0.47(0.18), z=-2.61, p<0.01)$.

\section{Duration of Females' Exploratory Behaviour on the Ground}

Model assumptions were verified (residuals in Appendix 9). Results show that the time females spend on the ground was not significantly influenced by the five acoustic parameters tested $\left(\mathrm{F}_{10-81}=\right.$ 1.27, $p=0.26, \mathrm{r}^{2}=0.03$ : Table 4, Fig. 5). The time females spent on the ground was not significantly different between the two burrow twosomes (estimate (SE) $=-0.47(0.30), z=-1.60, p=0.11$ ). duration. We observed that short calls attracted more skuas than long calls (Appendix 5).

\section{Discussion}



acoustic parameters of male calls (call rate, call duration, energy spectrum, number of syllables per phrase, and syllable rate) in blue petrels. Our two-choice playback experiments with modified calls successfully attracted females. The results indicate that more females were attracted by the high-pitched calls, by high-rate versions of the call exemplars tested, and possibly by modified calls with few syllablephrases. We found no relationships between acoustic parameters and time females spend on the ground exhibiting exploratory behaviours.

Results show that male calls attracted potential mates, even in absence of the caller. Similar results have been found in many taxa, including non-songbirds such as sage grouses and hoopoes (Gibson 1989; Martín-Vivaldi et al. 1999). Blue petrel females are attracted by vocal signals, even in absence of olfactory signals. Previous studies have assessed that olfactory signals contain genetic information about the signaller, and that they are likely to influence mate choice (Bonadonna \& Nevitt 2004; Bonadonna \& Sanz-Aguilar 2012; Leclaire et al. 2017). We thus hypothesize that both vocal and olfactory signals may influence mate choice but with a different timing: first, male calls may attract flying females, then olfactory signals may play a role when females land and/or when both male and female are in the burrow.

Results suggest that males calling with a high rate attract more flying females and more females on the ground. Similar results have been found in mammals and birds (McComb 1991; Riebel 2009). One possible explanation would be that males producing many frequent calls are easier to locate in dense and noisy colonies (up to two burrows per $\mathrm{m}^{2}$ : Brothers 1984) because the repetition of calls helps the female walking on the ground to locate the source of emission (Storey 1984). Producing redundant vocal signals is a communication strategy in response of misdetection and/or misclassification in noisy environment (“cocktail-party effect”: Cherry 1957). It has been well documented in seabirds, especially penguins (Aubin \& Jouventin 1998; Jouventin et al. 1999; Lengagne et al. 1999). A high call rate is also an indicator of sexual motivation in many birds, including burrowing petrels (Catchpole \& Slater 2008; Gémard et al. in prep; Searcy \& Beecher, 2009). Nonetheless, bachelor petrels face a high predation pressure and a high call rate also increases the risk of being detected by predators (Mougeot \& Bretagnolle 2000b). The handicap principle states that good-quality males take larger risks than other 
males to produce sexual signal (Zahavi 1975, 1977). Based on this theory, we could hypothesize for the blue petrels too that females are preferentially attracted by males that produce frequent calls, and thereby are more exposed to predation.

Our results also indicate that females are preferentially attracted by high-pitched calls when they fly over the colony. Although low frequencies are less attenuated by distance and environmental constrained (Marten et al. 1977), they are attenuated by the ground effect (Marten \& Marler 1977; Morton 1975), and some species are sensitive to high frequencies. A possibility is thus that calls higher in frequency might make the emitter easier to locate (Dooling 1982; Klump 2000; Park \& Dooling 1991), but so far little is known about how call frequency affects the ability of petrels to localize calls. Another possibility is that high-pitched calls indicate males of good-quality, as shown in many taxa, including tortoises (Galeotti et al. 2004), passerines (Cardoso et al. 2012), and mammals (Reby et al. 2010). In blue petrels, fundamental frequency may be related to bill morphology and body size: big males with a long, thin bill produce high-pitched calls (Gémard et al. 2019). In these filter-feeding seabirds, bill morphology may influence feeding efficiency (Klages \& Cooper 1992), and consequently the reproductive success.

Our results suggest that calls made of few-syllable phrases might be attractive to females. They contradict our assumptions that females may be preferentially attracted by long calls with many syllables. For example, in another non-songbirds, the hoopoe Upupa epops, songs with many syllables are more attractive than songs with few elements as it is an indication of the singer body condition (Martín-Vivaldi et al. 1998; Martín-Vivaldi et al. 2000). Moreover, males producing long calls with many elements are easier to detect and to locate than males producing short calls with few elements (Brumm \& Zollinger 2013), but this may be true both for potential mates and predators. We thus may hypothesize that females might be more attracted by males producing short calls with few syllables, but at a high call rate, as the result of a trade-off between predation avoidance and conspicuous sexual signalling.

Broadcast signals, regardless of the tested acoustic parameter, had no influence on the time attracted females spend on the ground, at the proximity of the burrow. In burrowing petrels, females vocalize towards the sound source (male in the burrow) when they are on the ground, and then walk 
following female-directed calls produced by males until they find the burrow entrance (Storey 1984). In blue petrels, males produce female-directed calls characterized by frequency and temporal modulations that may indicate their sexual motivation (Gémard et al. in prep). Olfactory signals may also be involved in sexual signalling because previous studies have shown burrows have a chemical signature (Bonadonna et al. 2001; Bonadonna et al. 2004), and individuals have a body odour containing genetic information (Bonadonna \& Nevitt 2004; Bonadonna \& Sanz-Aguilar 2012; Leclaire et al. 2017). Thus, we hypothesize that a necessary exchange of vocal and/or olfactory signals might take place before the female enters the burrow. In our experiments, we used a repetitive playback in an artificial burrow, so that we could not interactively reply in an appropriate way to a female close to the burrow, and no odours were emitted. In absence of these vocal and olfactory stimuli, and considering the predation risks (Mougeot \& Bretagnolle 2000b), females may fly rapidly away independently of the nature of the modified call emitted.

Results show that we recorded more females flying and, on the ground, when we tested the first burrow twosome (A) than when we tested the second twosome (B), likely because the number of bachelor males and females decreases over the breeding season, even though they are still active. Nonetheless, variations and significance of the attractiveness of the tested acoustic parameters were consistent between the two burrow twosomes.

Blue petrels are the main prey of the brown skua Stercorarius antarcticus, representing more call parameters.

To sum up, we showed for the first time in a burrowing petrel that males' calls are sexual signals, and that calls with certain acoustic characteristics are attractive to females. More precisely, females flying over the colony are more attracted by males producing high-pitched calls and calling at a high rate. Flying females might also be attracted preferentially by calls consisting in few-syllable phrases rather than many-syllable phrases. These acoustic parameters are related to male bill morphology and 
may thus be linked to male qualities, such as feeding efficiency. Another explanation is that males producing high-pitched calls at a high call rate may be easier to locate. Females are also attracted by short calls with few syllables, which make the caller less conspicuous. It might indicate a trade-off between predation avoidance and conspicuous sexual advertisement to attract potential mates in the hubbub of the colony. The time spent by females exploring on the ground might be influenced by additional signals, such as a vocal response from the male, olfactory signals, or both.

\section{References}

Amorim MCP (2006) Diversity of Sound Production in Fish. Diversity 1:71-105

Aubin T, Jouventin P (1998) Cocktail-party effect in king penguin colonies. Proc R Soc B Biol Sci 265:16651673. https://doi.org/10.1098/rspb.1998.0486

Ballentine B (2009) The ability to perform physically challenging songs predicts age and size in male swamp sparrows, Melospiza georgiana. Anim Behav 77:973-978. https://doi.org/10.1016/j.anbehav.2008.12.027

Ballentine B, Hyman J, Nowicki S (2004) Vocal performance influences female response to male bird song: an experimental test. Behav Ecol 15:163-168. https://doi.org/10.1093/beheco/arg090

Bates D, Maechler M, Bolker B, Walker S (2015) lme4: Linear mixed-effects models using Eigen and S4. 1-23

Bonadonna F, Nevitt GA (2004) Partner-specific odor recognition in an Antarctic seabird. Science (80- ) 306:835. https://doi.org/10.1126/science.1103001

Bonadonna F, Sanz-Aguilar A (2012) Kin recognition and inbreeding avoidance in wild birds: The first evidence for individual kin-related odour recognition. Anim Behav 84:509-513. https://doi.org/10.1016/j.anbehav.2012.06.014

Bonadonna F, Spaggiari J, Weimerskirch H (2001) Could osmotaxis explain the ability of blue petrels to return to their burrows at night? J Exp Biol 204:1485-1489

Bonadonna F, Villafane M, Bajzak C, Jouventin P (2004) Recognition of burrow's olfactory signature in blue petrels, Halobaena caerulea: an efficient discrimination mechanism in the dark. Anim Behav 67:893-898. https://doi.org/10.1016/j.anbehav.2003.08.013

Bretagnolle V (1990) Behavioural affinities of the blue petrel Halobaena caerulea. Ibis (Lond 1859) 132:102105. https://doi.org/10.1111/j.1474-919X.1990.tb01020.x

Bretagnolle V (1996) Acoustic communication in a group of nonpasserine birds, the petrels. In: Kroodsma DE, Miller EH (eds) Ecology and Evolution of Acoustic Communication in Birds, Cornell Un. New York, pp 
Bried J, Jouventin P (2001) Site and mate choice in seabirds: An evolutionary approach. In: Biology of Marine Birds. pp 263-305

Brothers NP (1984) Breeding, distribution and status of burrow-nesting petrels at Macquarie Island. Wildl Res 11:113-131. https://doi.org/10.1071/WR9840113

Brumm H, Zollinger SA (2013) Avian vocal production in noise. pp 187-227

Byers BE, Akresh ME, King DI (2016) Song and male quality in prairie warblers. Ethology 122:660-670. https://doi.org/10.1111/eth.12513

Cardoso GC (2012) Paradoxical calls: the opposite signaling role of sound frequency across bird species. Behav Ecol 23:237-241. https://doi.org/10.1093/beheco/arr200

Catchpole CK, Slater PJB (2008) Bird song: biological themes and variations

Chastel O, Weimerskirch H, Jouventin P (1995) Body condition and seabird reproductive performance: a study of three petrel species. Ecology 76:2240-2246. https://doi.org/10.2307/1941698

Cherry C (1957) On human communication; a review, a survey, and a criticism

Christensen R, Kleindorfer S, Robertson J (2006) Song is a reliable signal of bill morphology in Darwin's small tree finch Camarhynchus parvulus, and vocal performance predicts male pairing success. J Avian Biol 37:617-624. https://doi.org/10.1111/j.0908-8857.2006.03684.x

Courtiol A, Etienne L, Feron R, et al (2016) The evolution of mutual mate choice under direct benefits. Am Nat 188:521-538. https://doi.org/10.1086/688658

Dooling RJ (1982) Auditory perception in birds. In: Kroodsma D, Miller E (eds) Acoustic Communication in Birds, Vol. 1. New York: Academic Press, pp 95-130

Favaro L, Gamba M, Gili C, Pessani D (2017) Acoustic correlates of body size and individual identity in banded penguins. PLoS One 12:e0170001. https://doi.org/10.1371/journal.pone.0170001

Galeotti P, Sacchi R, Rosa DP, Fasola M (2005) Female preference for fast-rate, high-pitched calls in Hermann's tortoises Testudo hermanni. Behav Ecol 16:301-308. https://doi.org/10.1093/beheco/arh165

Gémard C, Aubin T, Bonadonna F (2019) Males' calls carry information about individual identity and morphological characteristics of the caller in burrowing petrels. J Avian Biol jav.02270. https://doi.org/10.1111/jav.02270

Genevois F, Bretagnolle V (1994) Male blue petrels reveal their body mass when calling. Ethol Ecol Evol 6:377-383. https://doi.org/10.1080/08927014.1994.9522988 
Gibson RM (1989) Field playback of male display attracts females in lek breeding sage grouse. Behav Ecol Sociobiol 24:439-443. https://doi.org/10.1007/BF00293273

Halliday T (1983) The study of mate choice. In: P. Bateson (ed) Mate choice. Cambridge University Press, Cambridge, pp 3-32

Jouventin P, Aubin T, Lengagne T (1999) Finding a parent in a king penguin colony: the acoustic system of individual recognition. Anim Behav 57:1175-1183. https://doi.org/10.1163/156853999501595

Jouventin P, Mougin J-L (1981) Les stratégies adaptatives des oiseaux de mer. Rev Ecol (Terre vie) 35:217-249

Klages NTW, Cooper J (1992) Bill morphology and diet of a filter- feeding seabird: the broad- billed prion Pachyptila vittata at South Atlantic Gough Island. J Zool 227:385-396. https://doi.org/10.1111/j.14697998.1992.tb04401.x

Klump GM (2000) Sound localization in birds. In: Dooling RJ, Fay RR, Popper AN (eds) Comparative Hearing: Birds and Reptiles. Springer New York, pp 249-307

Knörnschild M, Blüml S, Steidl P, et al (2017) Bat songs as acoustic beacons - Male territorial songs attract dispersing females. Sci Rep 7:1-11. https://doi.org/10.1038/s41598-017-14434-5

Kriesell HJ, Aubin T, Planas-Bielsa V, et al (2018) Sex identification in king penguins Aptenodytes patagonicus through morphological and acoustic cues. Ibis (Lond 1859) 160:755-768. https://doi.org/10.1111/ibi.12577

Leclaire S, Strandh M, Mardon J, et al (2017) Odour-based discrimination of similarity at the major histocompatibility complex in birds. Proc R Soc B Biol Sci 284:2016-20466. https://doi.org/10.1098/rspb.2016.2466

Lengagne T, Aubin T, Lauga J, Jouventin P (1999) How do king penguins (Aptenodytes patagonicus) apply the mathematical theory of information to communicate in windy conditions? Proc R Soc B Biol Sci 266:1623-1628. https://doi.org/10.1098/rspb.1999.0824

Marten K, Quine D, Marler P (1977) Sound transmission and its significance for animal vocalization. Behav Ecol Sociobiol 2:291-302. https://doi.org/10.1007/BF00299741

Martín-Vivaldi M, Palomino JJ, Soler M (2000) Attraction of hoopoe Upupa epops females and males by means of song playback in the field: influence of strophe length. J Avian Biol 31:351-359. https://doi.org/10.1034/j.1600-048X.2000.310311.x

Martín-Vivaldi M, Palomino JJ, Soler M (1999) Function of song in the hoopoe Upupa epops. Bird Study 46:104-111. https://doi.org/10.1080/00063659909461120 
Martín-Vivaldi M, Palomino JJ, Soler M (1998) Song structure in the hoopoe (Upupa epops) - Strophe length reflects male condition. J fur Ornithol 139:287-296. https://doi.org/10.1007/BF01653339

McComb KE (1991) Female choice for high roaring rates in red deer, Cervus elaphus. Anim Behav 41:79-88. https://doi.org/10.1016/S0003-3472(05)80504-4

Moncorps S, Chapuis JL, Haubreux D, Bretagnolle V (1998) Diet of the brown skua Catharacta skua lönnbergi on the Kerguelen archipelago: comparisons between techniques and between islands. Polar Biol 19:9-16. https://doi.org/10.1007/s003000050210

Morton ES (1975) Ecological Sources of Selection on Avian Sounds. Am Nat 109:17-34. https://doi.org/10.1086/282971

Mougeot F, Bretagnolle V (2000a) Predation risk and moonlight avoidance in nocturnal seabirds. J Avian Biol 31:376-386. https://doi.org/10.1034/j.1600-048X.2000.310314.x

Mougeot F, Bretagnolle V (2000b) Predation as a cost of sexual communication in nocturnal seabirds: an experimental approach using acoustic signals. Anim Behav 60:647-656. https://doi.org/10.1006/anbe.2000.1491

Mougeot F, Genevois F, Bretagnolle V (1998) Predation on burrowing petrels by the brown skua (Catharacta skua lönnbergi) at Mayes Island, Kerguelen. J Zool 244:429-438. https://doi.org/10.1017/S0952836998003136

Mountjoy DJ, Lemon RE (1991) Song as an attractant for male and female European starlings, and the influence of song complexity on their response. Behav Ecol Sociobiol 28:97-100. https://doi.org/10.1007/BF00180986

Park TJ, Dooling RJ (1991) Sound localization in small birds: absolute localization in azimuth. J Comp Psychol 105:125-133. https://doi.org/10.1037/0735-7036.105.2.125

Quillfeldt P, Masello JF, Segelbacher G (2012) Extra-pair paternity in seabirds: a review and case study of thinbilled prions Pachyptila belcheri. J Ornithol 153:367-373. https://doi.org/10.1007/s10336-011-0751-9

Reby D, Charlton BD, Locatelli Y, McComb K (2010) Oestrous red deer hinds prefer male roars with higher fundamental frequencies. Proc R Soc B Biol Sci 277:2747-2753. https://doi.org/10.1098/rspb.2010.0467

Riebel K (2009) Song and female mate choice in zebra finches: A review. In: Advances in the Study of Behavior, 1st edn. Elsevier Inc., pp 197-238

Ryan MJ (1980) Female mate choice in a neotropical frog. Science (80- ) 209:523-525. https://doi.org/10.1126/science.209.4455.523 
Salton M, Saraux C, Dann P, Chiaradia A (2015) Carry-over body mass effect from winter to breeding in a resident seabird, the little penguin. R Soc Open Sci 2:140390-140390. https://doi.org/10.1098/rsos.140390

Schreiber EA, Burger J (eds) (2001) Biology of Marine Birds. CRC Press, Boca Raton, London, New York, Washington DC

Searcy WA, Andersson M (1986) Sexual selection and the evolution of song. Annu Rev Ecol Syst 17:507-533. https://doi.org/10.1146/annurev.es.17.110186.002451

Searcy WA, Beecher MD (2009) Song as an aggressive signal in songbirds. Anim Behav 78:1281-1292. https://doi.org/10.1016/j.anbehav.2009.08.011

Smith JM (1991) Theories of sexual selection. Trends Ecol Evol 6:146-151. https://doi.org/10.1016/01695347(91)90055-3

Specht R (2002) Avisoft-saslab pro: sound analysis and synthesis laboratory. Berlin

Storey AE (1984) Function of Manx shearwater calls in mate attraction. Behaviour 89:73-89

Walling, Cheves; Rabinowitz R (1957) Studies on the acoustical behavior and taxonomy of the tree crickets (Orthoptera: Oecanthinae) of the eastern United States. The Ohio States University

Warham J (1990) The petrels: their ecology and breeding systems. London

Warham J (1996) Behaviour and vocalizations of Procellaridae, Hydrobatidae and Pelecoididae. In: The Behaviour, Population Biology and Physiology of the Petrels. Elsevier

Weimerskirch H, Chastel O, Ackermann L (1995) Adjustment of parental effort to manipulated foraging ability in a pelagic seabird, the thin-billed prion Pachyptila belcheri. Behav Ecol Sociobiol 36:11-16. https://doi.org/10.1007/BF00175723

Zahavi A (1977) The cost of honesty. Further remarks on the handicap principle. J Theor Biol 67:603-605. https://doi.org/10.1016/0022-5193(77)90061-3

Zahavi A (1975) Mate selection — A selection for a handicap. J Theor Biol 53:205-214. https://doi.org/10.1016/0022-5193(75)90111-3

Zuk M, Kolluru GR (1998) Exploitation of Sexual Signals by Predators and Parasitoids. Q Rev Biol 73:415-438. https://doi.org/10.1086/420412 


\section{FIGURE CAPTIONS}

492 Fig. 1 Spectrogram (top) and oscillogram (bottom) of a two-phrase call of a male blue petrel Halobaena caerulea.

493 Letters from A to D represent the four syllable types constituting a phrase.

494 Fig. 2 Experimental installation on the field. Grey triangles represent the field of view of each phototrap.

495 Fig. 3 Number of blue petrel females flying at a maximum distance of five meters from the burrow where

496 modified calls of male blue petrel were broadcast (in percentage). Lines link the two burrows of a burrow

497 twosome where we broadcast a stimuli dyad

498 Fig. 4 Number of blue petrel females showing exploratory behaviours on the ground at proximity of the burrow

499 where modified calls of male blue petrel were broadcast (in percentage). Lines link the two burrows of a burrow

500 twosome where we broadcast a stimuli dyad

501 Fig. 5 Time spent by blue petrel females showing exploratory behaviours on the ground, at proximity of the

502 burrow where modified calls of male blue petrel were broadcast 
Fig. 1

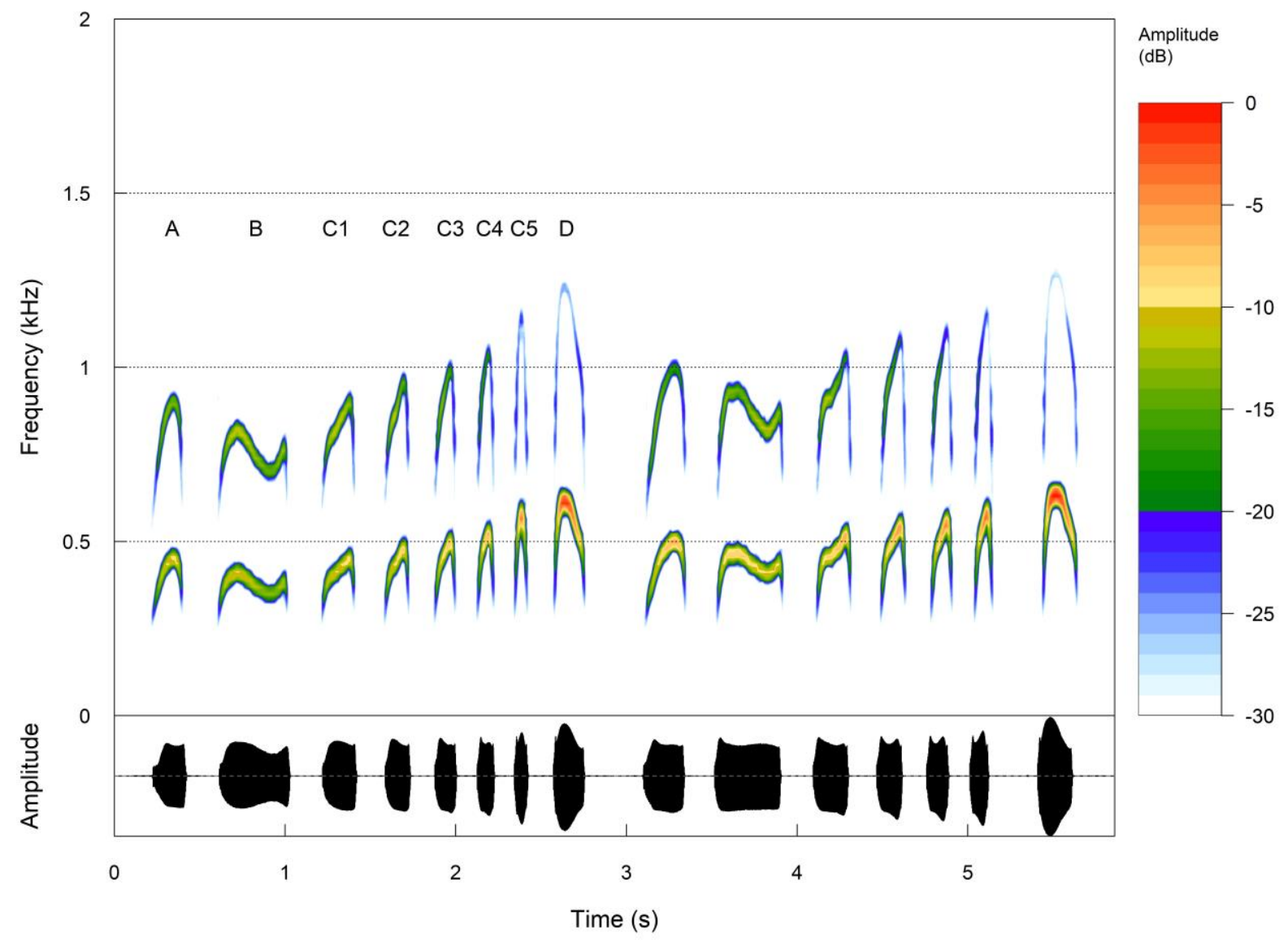


Fig. 2

Phototrap 1

Phototrap 2

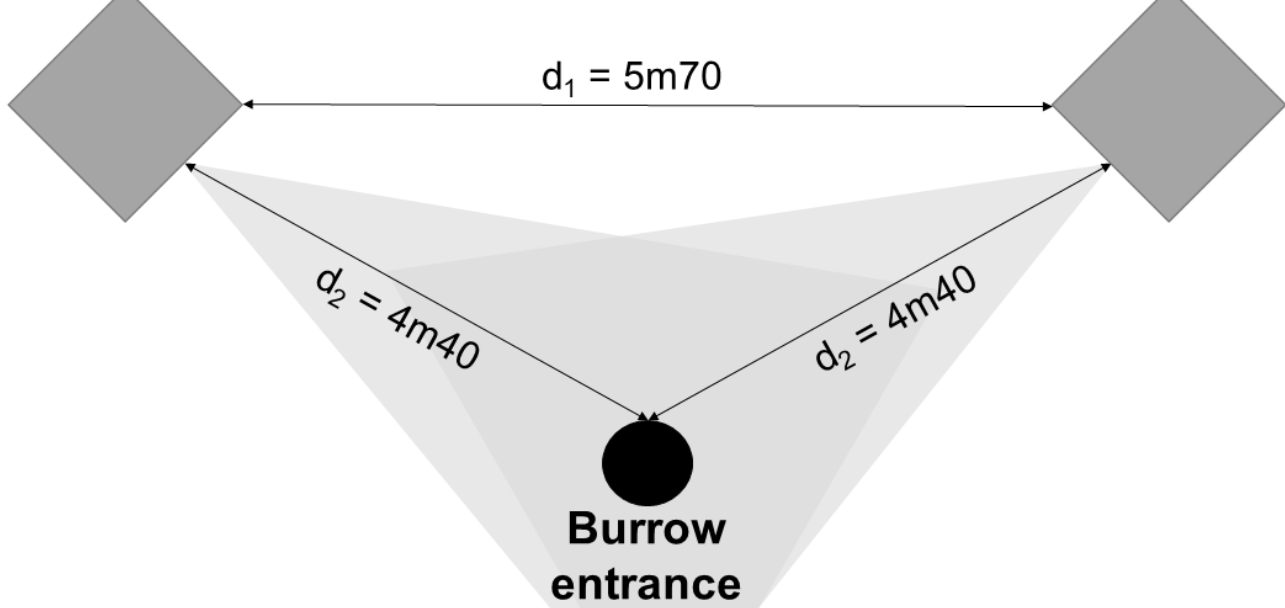


Fig. 3

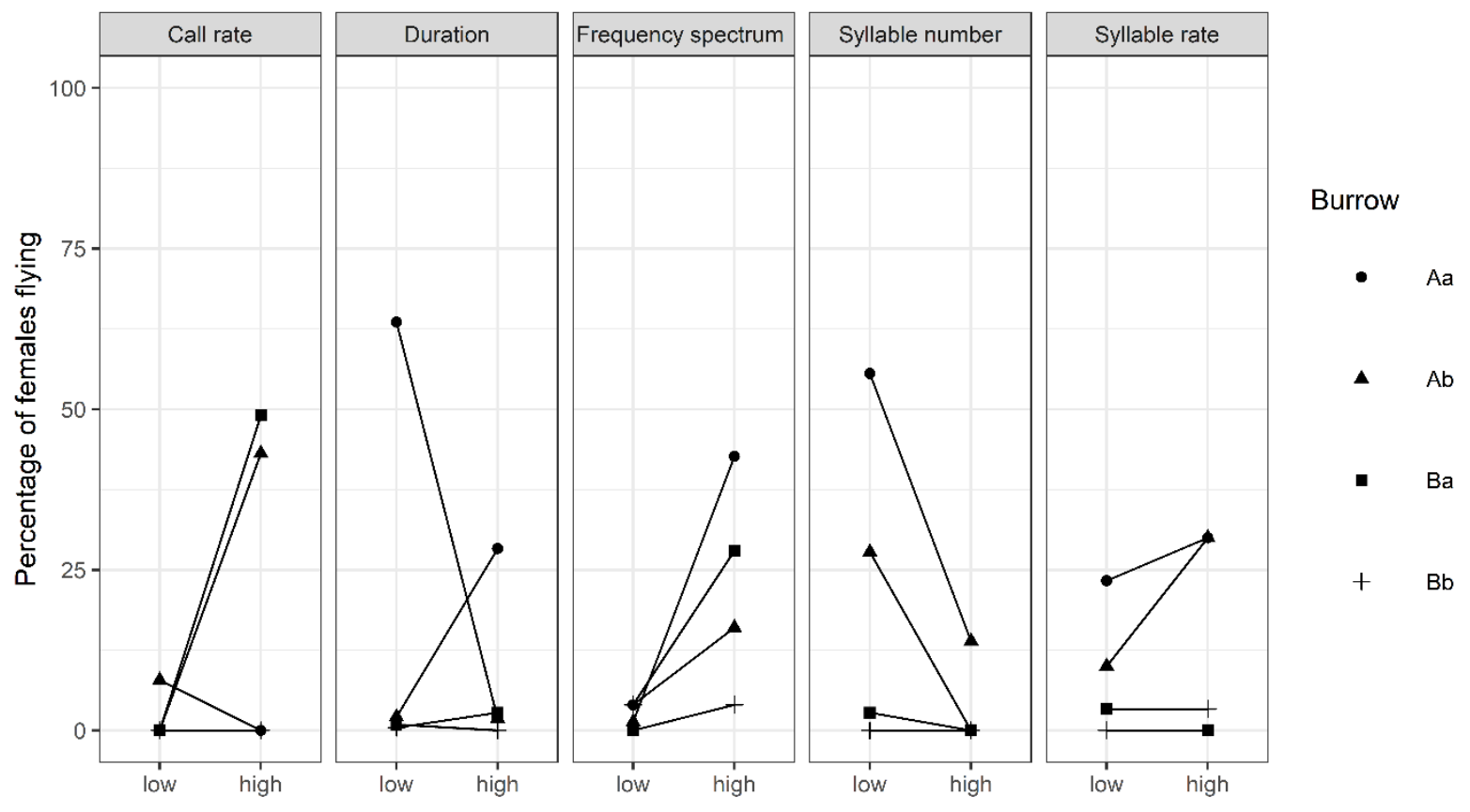


Fig. 4
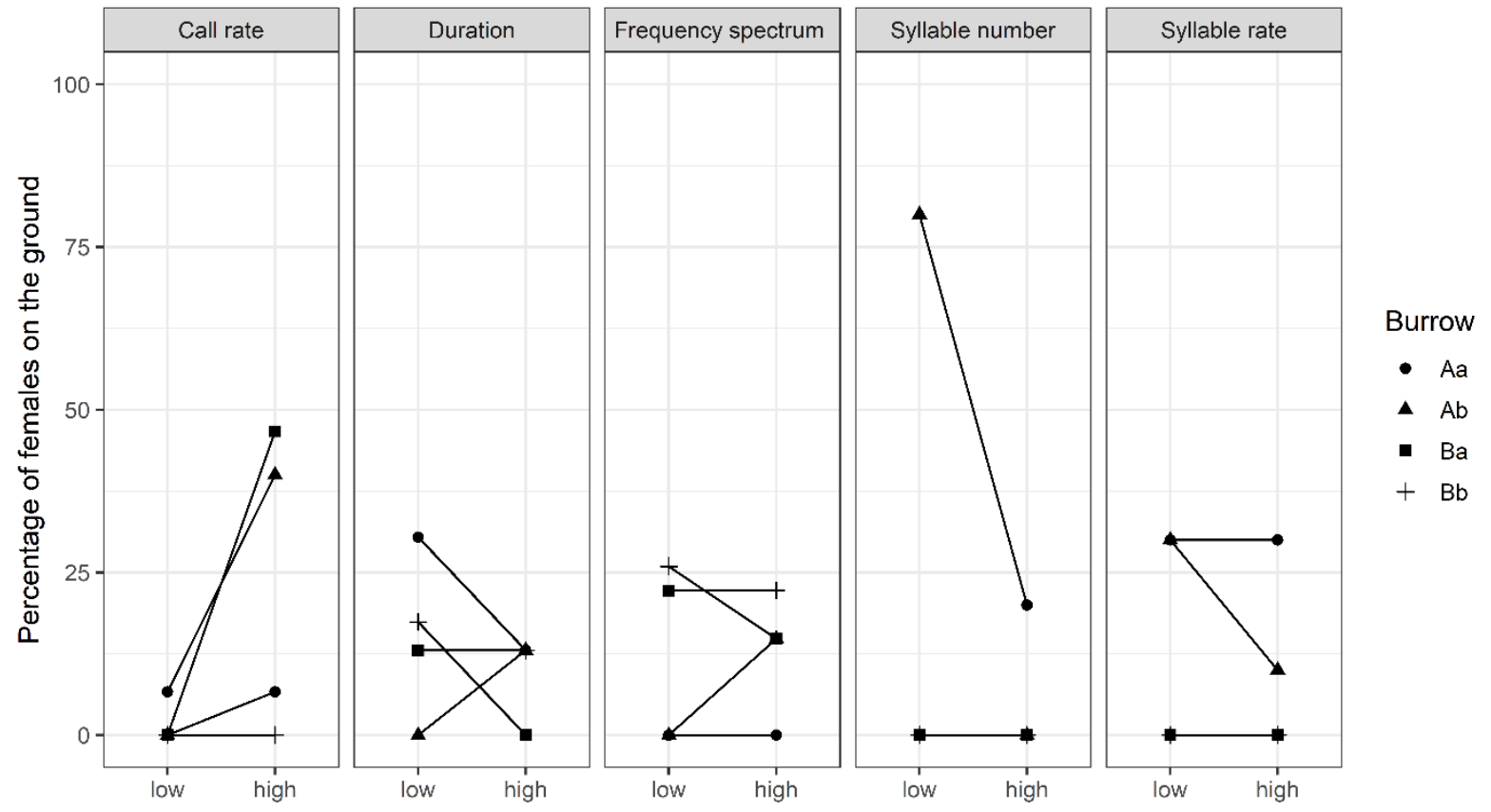
Fig. 5

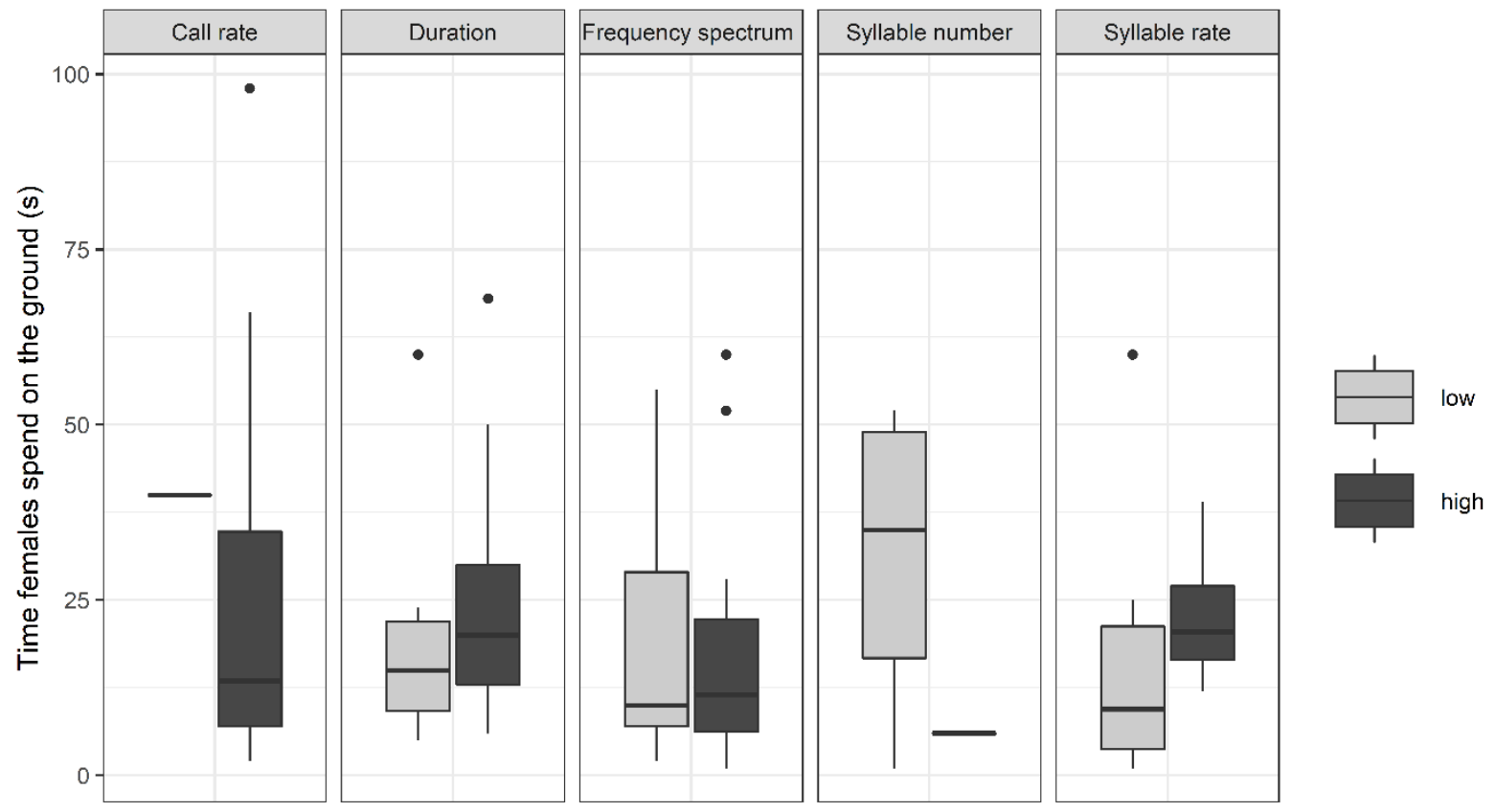


Table 1 Dyads of experiment signals broadcast to test the attractiveness of different acoustic traits

$\begin{array}{ccc}\text { Acoustic trait } & \text { Low } & \text { High } \\ \text { Call rate } & 1 \text { call/3 min } & 1 \text { call/30 sec } \\ \text { Call duration } & 2 \text { phrases } & 8 \text { phrases } \\ \text { Call energy spectrum } & -50 \mathrm{~Hz} & +50 \mathrm{~Hz} \\ \text { Number of syllables per phrase } & 2 \text { syllables C } & 6 \text { syllables C } \\ \text { Syllable rate } & -50 \% \text { inter-syllable silence } & +50 \% \text { inter-syllable silence }\end{array}$

Table 2 NB GLM contrasts between high-trait-call and the low-trait-call for each acoustic trait. Significant contrasts $(* p<0.05)$ are in bold

\begin{tabular}{ccccccc} 
Acoustic traits & Estimate & SE & $\boldsymbol{z}$ value & \multicolumn{2}{c}{$\boldsymbol{p}$ value } & \\
Call rate & 2.12 & 0.90 & 2.35 & $\mathbf{0 . 0 2}$ & $*$ \\
Duration & -0.25 & 0.84 & -0.30 & 0.77 & \\
Energy spectrum & 1.94 & 0.89 & 2.18 & $\mathbf{0 . 0 3}$ & $*$ \\
Number of syllables & -1.94 & 1.03 & -1.88 & 0.06 & $*$ \\
Syllable rate & 0.24 & 0.98 & 0.24 & 0.81 & \\
\hline
\end{tabular}

Table 3 GLM contrasts between high-trait-call and the low-trait-call for each acoustic trait. Significant contrasts $(* p<0.05)$ are in bold

\begin{tabular}{ccccc} 
Acoustic traits & Estimate & SE & $\boldsymbol{z}$ value & $\boldsymbol{p}$ value \\
Call rate & 1.22 & 0.51 & 2.41 & $\mathbf{0 . 0 2}$ \\
Duration & -0.46 & 0.31 & -1.49 & 0.14 \\
Energy spectrum & 0.18 & 0.35 & 0.52 & 0.60 \\
Number of syllables & -1.79 & 1.08 & -1.66 & 0.10 \\
Syllable rate & -0.34 & 0.41 & -0.81 & 0.42 \\
\hline
\end{tabular}

Table 4 Linear Model contrasts between the high-trait-call and the low-trait-call for each acoustic trait. Significant contrasts $(* p<0.05)$ are in bold

\begin{tabular}{ccccc} 
Acoustic traits & Estimate & SE & $\boldsymbol{t}$ value & $\boldsymbol{p}$ value \\
Call rate & -1.04 & 0.66 & -1.71 & 0.09 \\
Duration & 0.15 & 0.46 & 0.32 & 0.75 \\
Energy spectrum & -0.18 & 0.39 & -0.46 & 0.65 \\
Number of syllables & -0.94 & 1.18 & -0.79 & 0.43 \\
Syllable rate & 0.53 & 0.60 & 0.88 & 0.38 \\
\hline
\end{tabular}

